\title{
Efficacy and safety of venous thromboembolism prophylaxis with apixaban in major orthopedic
}

\section{surgery}

\author{
Sebastian Werth \\ Kai Halbritter \\ Jan Beyer-Westendorf \\ Center for Vascular Medicine \\ and Department of Medicine III, \\ Division of Angiology, University \\ Hospital "Carl Gustav Carus" \\ Dresden, Dresden, Germany
}

This article was published in the following Dove Press journal:

Therapeutics and Clinical Risk Management

22 March 2012

Number of times this article has been viewed

\begin{abstract}
Over the last 15 years, low-molecular-weight heparins (LMWHs) have been accepted as the "gold standard" for pharmaceutical thromboprophylaxis in patients at high risk of venous thromboembolism (VTE) in most countries around the world. Patients undergoing major orthopedic surgery (MOS) represent a population with high risk of VTE, which may remain asymptomatic or become symptomatic as deep vein thrombosis or pulmonary embolism. Numerous trials have investigated LMWH thromboprophylaxis in this population and demonstrated high efficacy and safety of these substances. However, LMWHs have a number of disadvantages, which limit the acceptance of patients and physicians, especially in prolonged prophylaxis up to 35 days after MOS. Consequently, new oral anticoagulants (NOACs) were developed that are of synthetic origin and act as direct and very specific inhibitors of different factors in the coagulation cascade. The most developed NOACs are dabigatran, rivaroxaban, and apixaban, all of which are approved for thromboprophylaxis in MOS in a number of countries around the world. This review is focused on the pharmacological characteristics of apixaban in comparison with other NOACs, on the impact of NOAC on VTE prophylaxis in daily care, and on the management of specific situations such as bleeding complications during NOAC therapy.
\end{abstract}

Keywords: major orthopedic surgery, apixaban, dabigatran, edoxaban, rivaroxaban, deep vein thrombosis, venous thromboembolism, VTE prophylaxis

\section{Introduction}

Over the last 15 years, low-molecular-weight heparins (LMWHs) have been accepted as the "gold standard" for pharmaceutical thromboprophylaxis in patients at high risk of venous thromboembolism (VTE) in most countries around the world. ${ }^{1,2}$ Patients undergoing major orthopedic surgery (MOS) represent a population with high risk of VTE, which may be found asymptomatic in screening exams or present as symptomatic events such as deep vein thrombosis (DVT) or pulmonary embolism (PE). Numerous trials have investigated LMWH thromboprophylaxis in this population and demonstrated high efficacy and safety of these drugs. ${ }^{3-6}$ However, LMWHs have a number of disadvantages. First of all, daily injections of parenteral anticoagulants are cumbersome and impair the quality of life of patients, especially in prolonged prophylaxis up to 35 days after MOS. ${ }^{7}$ Furthermore, allergic skin reactions are quite common, and cases of heparin-induced thrombocytopenia, however rare, demonstrate potentially life-threatening complications of heparin therapy. Therefore, frequent monitoring of platelet count is necessary during LMWH exposure.
Correspondence: Jan Beyer-Westendorf Center for Vascular Medicine, University Hospital "Carl Gustav Carus", Technical University Dresden, Fetscherstrasse 74; 01307 Dresden, Germany

Tel $+4935 \mid 4583659$

Fax +49 531 4584359

Email jan.beyer@uniklinikum-dresden.de 
Finally, LMWHs are derived from animal sources, and manufactures have faced changes in the processing methods and hygiene problems in the past. Consequently, production costs will remain comparatively high and might even increase in future. ${ }^{8}$ Some of these problems could be resolved by using the synthetic indirect factor Xa inhibitor fondaparinux, which has been shown to be highly effective in VTE prevention after MOS. ${ }^{9}$ On the other hand, fondaparinux also needs to be injected daily and, at least in some countries, is associated with high costs.

All of these problems with parenteral thromboprophylaxis provide the medical background for the development of new oral anticoagulants (NOACs). These are of synthetic origin and act as direct and very specific inhibitors of different factors in the coagulation cascade. The most developed NOACs are dabigatran, rivaroxaban, and apixaban, all of which are approved for thromboprophylaxis in MOS in a number of countries around the world, based on large Phase III trials demonstrating favorable efficacy and safety results compared with LMWH prophylaxis. ${ }^{10-16}$ Another factor Xa inhibitor, edoxaban, has also been tested in patients undergoing MOS but is currently not approved. ${ }^{17,18}$

This review is focused on the pharmacological characteristics of apixaban in comparison with other NOACs and on the impact of apixaban on the management of VTE prophylaxis in patients undergoing MOS.

\section{Pharmacological characteristics of apixaban and other new oral anticoagulants}

Activation of factor $\mathrm{X}$ to factor $\mathrm{Xa}$ (FXa) plays a central role in the cascade of blood coagulation. FXa directly converts prothrombin to thrombin through the prothrombinase complex, which leads to fibrin clot formation and activation of platelets by thrombin. A single molecule of FXa is able to generate more than 1000 molecules of thrombin due to the amplification nature of the coagulation cascade. Furthermore, the reaction rate of prothrombinase-bound $\mathrm{FXa}$ increases 300,000-fold compared with that of free FXa. Therefore, factor X activation and binding in the prothrombinase complex causes an explosive burst of thrombin generation.

New orally acting substances have been developed to inhibit FXa selectively (FXa inhibitors such as apixaban, rivaroxaban, or edoxaban), prevent this burst of thrombin generation, or inhibit the excessively generated thrombin (direct thrombin inhibitors such as dabigatran).

Apixaban is a small molecule with a molecular weight of $460 \mathrm{Da}$, which inhibits factor Xa reversibly and additionally inhibits trypsin and thrombin generation. In addition to inhibiting circulating factor $\mathrm{Xa}$, apixaban also blocks factor $\mathrm{Xa}$ bound within the prothrombinase complex or factor $\mathrm{Xa}$ activity within the clot (Figure 1). ${ }^{19,20}$

After oral intake, apixaban is rapidly absorbed with bioavailability in the stomach and small intestine of approximately $66 \%$ and a high protein binding of $87 \% .^{21,22}$ Maximum concentration levels are seen after 1-3 hours. The half-life of apixaban is 8-15 hours in young subjects after metabolism by a cytochrome P450 (CYP)3A4-related pathway with $25 \%$ renal excretion and $55 \%$ elimination by the feces (Table 1). ${ }^{23,24}$

The other new oral factor Xa inhibitors rivaroxaban (molecular weight of $436 \mathrm{Da}$ ) and edoxaban (molecular weight of $536 \mathrm{Da}$ ) were also found to inhibit free and clotbound factor Xa, which seems to be a class effect of all new oral factor Xa inhibitors. ${ }^{25,26}$ Of note, rivaroxaban does not inhibit other serine proteases such as trypsin. ${ }^{27}$

The bioavailability of rivaroxaban is approximately $100 \%$ with plasma protein binding above $90 \%$ and metabolism via CYP3A4-, CYP2C8-, and CYP-independent mechanisms. Thirty to forty percent of the substance is renally excreted as unchanged drug, whereas $30 \%$ is renally excreted as inactive metabolits and the remainder is excreted as unchanged drug in the feces. ${ }^{28-31}$ The intestinal excretion appears to be mediated by p-glycoprotein ( $\mathrm{p}-\mathrm{Gp}$ ) - an intestinal drug transporter - so potent $\mathrm{p}-\mathrm{Gp}$ inhibitors may increase drug concentrations. ${ }^{32}$ The half-life ranges between 5 hours and 9 hours in healthy subjects and between 11 hours and 13 hours in elderly subjects. ${ }^{33-36}$

Compared with apixaban and rivaroxaban, edoxaban has a lower bioavailability of around $50 \%$ and a half-life of 9-11 hours in young healthy subjects with a combined elimination pathway: $35 \%$ is renally excreted (24\% active metabolite) and $62 \%$ is excreted via feces. ${ }^{37-39}$ Edoxaban is also a substrate of $\mathrm{p}-\mathrm{Gp}$, so strong inhibitors could lead to a higher concentration of edoxaban. ${ }^{40}$ The metabolism in liver microsomes is mediated mainly by CYP3A4-related pathways. ${ }^{41}$

In contrast to these oral factor Xa inhibitors, dabigatran is an oral direct thrombin inhibitor (Figure 1), which binds to the active binding site of thrombin (free and clot-bound thrombin) and inhibits its activation. Dabigatran exhibits a pharmacological profile different from that of FXA inhibitors (Table 1). Given as a prodrug (dabigatran etexilate), the substance is rapidly absorbed. ${ }^{42}$ However, dissolution and absorption require an acidic microenvironment, and therefore dabigatran etexilate capsules contain a core of tartaric acid to stabilize the variations in gastric $\mathrm{pH}$. Despite this, 


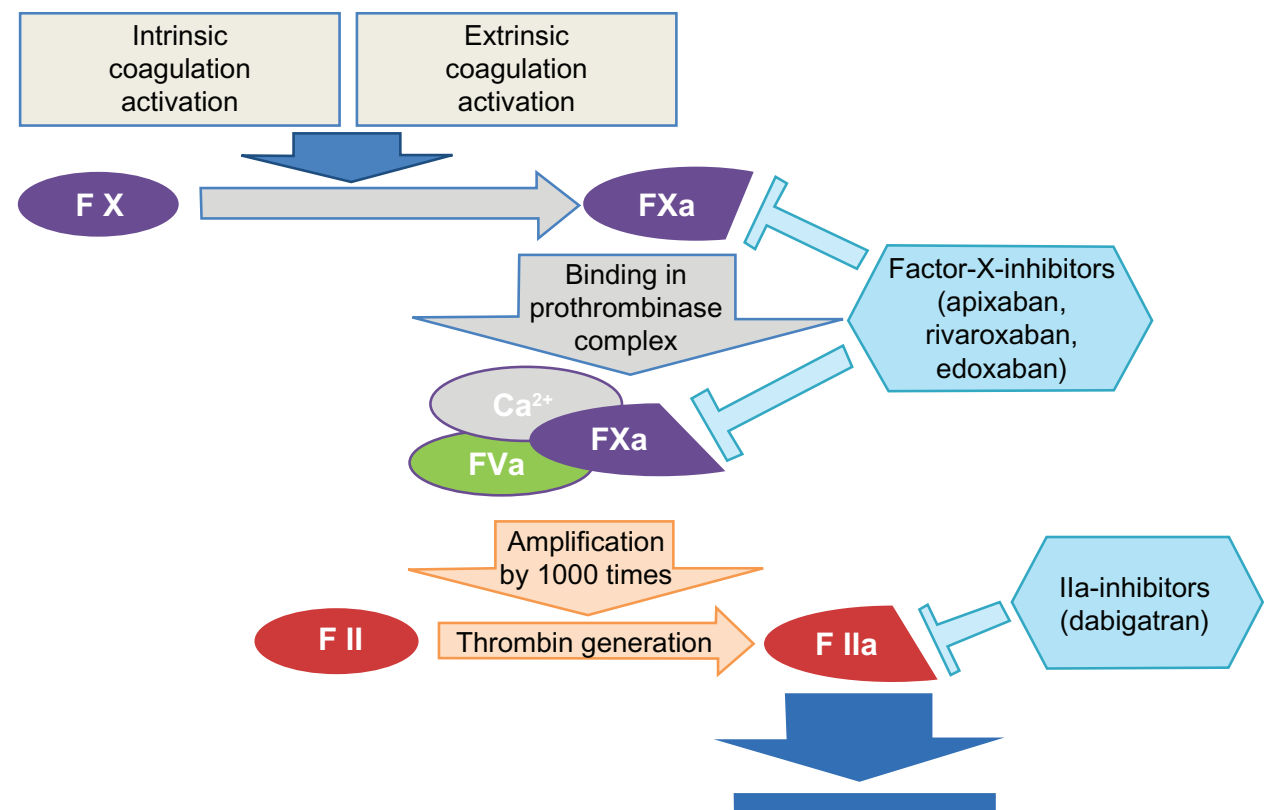

Clot formation

Figure I Simplified model of coagulation activation, clot formation, and mode of action of new oral anticoagulants.

Notes: Intrinsic and extrinsic coagulation activation leads to activation of factor $\mathrm{X}$ ( $\mathrm{FXa}$ ), which is bound into the prothrombinase complex consisting of phospholipids, calcium $\left(\mathrm{Ca}^{2+}\right)$, activated factor $\mathrm{V}(\mathrm{FVa})$, and $\mathrm{FXa}$. Bound in this complex, a singe molecule of $\mathrm{FXa}$ can activate degredation of $\mathrm{I} 000$ molecules of prothrombin ( $\left.\mathrm{FI}\right)$ to active thrombin ( $\mathrm{F} \mathrm{lla}$ ), which ultimately induces clot formation. Factor Xa inhibitors inhibit both free and complex-bound active factor Xa. On the other hand, direct thrombin inhibitors (factor II inhibitors) inactivate the thrombin generated by coagulation activation.

oral bioavailability is low with values around $6 \%$. Peak plasma concentrations of dabigatran are reached approximately 2 hours after oral administration. Half-life in healthy volunteers is $12-17$ hours but prolonged in elderly patients or patients with impaired renal function, because nearly $90 \%$ of dabigatran is renally excreted. Dabigatran is not metabolized by CYP450 isoenzymes.

\section{Drug-drug interactions of NOACs}

With apixaban, pharmacological interactions are seen with comedications of azol-type antimycotics such as ketoconazol or HIV-protease inhibitors such as ritonavir, which result in an increase of the area under the curve and the maximum concentration for apixaban, potentially increasing bleeding risks. Therefore, apixaban treatment is contraindicated in patients receiving these drugs. Similar interactions are seen with rivaroxaban and edoxaban. ${ }^{35}$ On the other hand, coadministration of rifampicin leads to a significantly lower area under the curve and thereby to a significantly lower efficacy of apixaban, rivaroxaban, or edoxaban, which needs to be considered because insufficient anticoagulant efficacy may result from this interaction.

In patients receiving dabigatran, concomitant treatment with strong $\mathrm{p}-\mathrm{G}$ p inhibitors like amiodaron, verapamil, chinidin,

Table I Pharmacological profile of new oral anticoagulants: direct factor Xa inhibitors rivaroxaban, apixaban, and edoxaban and direct thrombin inhibitor dabigatran

\begin{tabular}{|c|c|c|c|c|}
\hline Drug & Rivaroxaban & Apixaban & Edoxaban & Dabigatran \\
\hline Target & $\mathrm{Xa}$ & $\mathrm{Xa}$ & $\mathrm{Xa}$ & Ila \\
\hline VTE prophylaxis dose & 10 mg OD & $2.5 \mathrm{mg}$ BID & (Japan only: 30 mg OD) & $220 \mathrm{mg}$ OD (I50 mg OD for $\mathrm{CrCl} 30-50 \mathrm{~mL} / \mathrm{min}$ \\
\hline $\begin{array}{l}\text { Time and dosage of first } \\
\text { application post surgery }\end{array}$ & $6-10 \mathrm{~h} ; 10 \mathrm{mg}$ & I2-24 h; $2.5 \mathrm{mg}$ & (Japan only: 6-8 h; 30 mg) & $\mathrm{I}-4 \mathrm{~h} ; \mathrm{I} 10 \mathrm{mg}$ (75 mg for $\mathrm{CrCl} 30-50 \mathrm{~mL} / \mathrm{min})$ \\
\hline Bioavailability & Up to $100 \%$ & $66 \%$ & $50 \%$ & $6 \%$ \\
\hline Half-life & $5-13 \mathrm{~h}$ & $8-15 \mathrm{~h}$ & $9-I I h$ & $12-17 \mathrm{~h}$ \\
\hline Renal elimination & $40 \%$ & $25 \%$ & $35 \%$ & $85 \%$ \\
\hline Interactions & $\begin{array}{l}\text { CYP3A4/p-Gp } \\
\text { inhibitors }\end{array}$ & $\begin{array}{l}\text { CYP3A4/p-Gp } \\
\text { inhibitors }\end{array}$ & CYP3A4/p-Gp inhibitors & p-Gp inhibitors \\
\hline
\end{tabular}

Abbreviations: BID, twice daily; $\mathrm{CrCl}$, creatinine clearance; CYP, cytochrome P450; OD, once daily; p-Gp, p-glycoprotein; VTE, venous thromboembolism. 
A

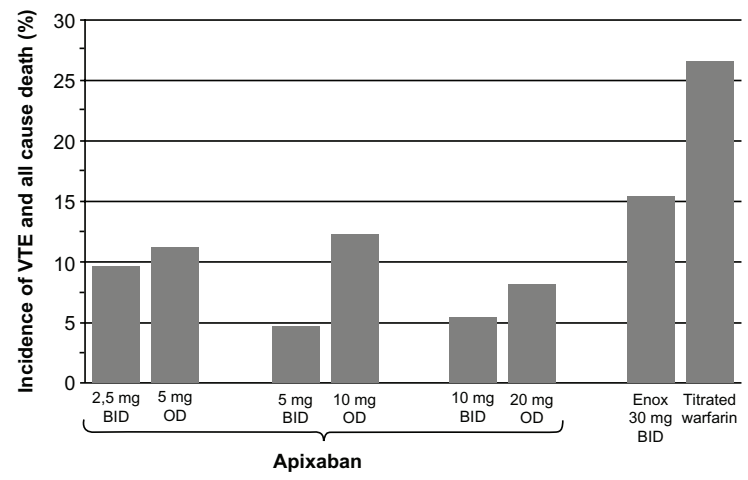

B

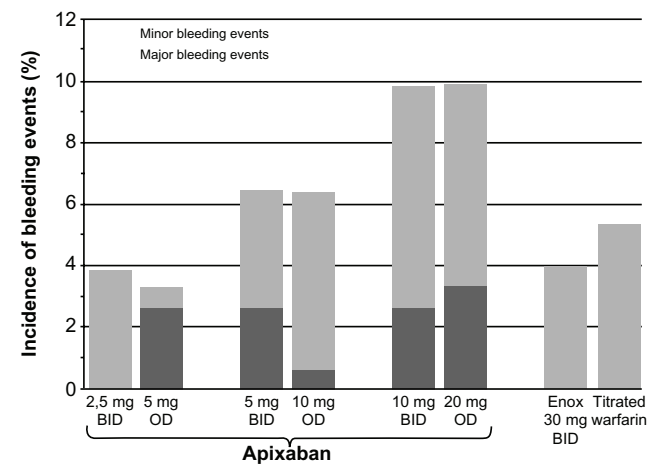

Figure 2 Results of a Phase II dose-finding study of apixaban versus enoxaparin or international normalized ratio titrated warfarin in patients undergoing major orthopedic surgery. ${ }^{43}$

Notes: All dosages of apixaban and both once- and twice-daily regimens were highly effective in venous thromboembolism prevention (left). Apixaban 2.5 mg twice daily had the lowest rates of major bleeding complications. Furthermore, increasing daily dosages led to a linear increase of bleeding complications in both once-daily and twice-daily regimens, but major bleeding complications were rare in all treatment arms (right).

Abbreviations: BID, twice daily; OD, once daily.

or clarithromycin leads to higher plasma concentrations of dabigatran, requiring a dose reduction. Furthermore, the combination of dabigatran and ketoconazole, ciclosporin, itraconazol, and tacrolimus is prohibited. Due to the reduction of dabigatran plasma concentrations, concomitant therapy with St Johns wort or rifampicin is not recommended.

\section{Clinical trials of apixaban in major orthopedic surgery}

Dose-response relationship and the safety of escalating doses of apixaban were tested in a trial comparing enoxaparin twice daily $30 \mathrm{mg}$ subcutaneously, open-label warfarin target international normalized ratio (INR) 1.8-3.0, and six double-blind apixaban doses $5 \mathrm{mg}, 10 \mathrm{mg}$, and $20 \mathrm{mg}$ daily as once- or twice-daily divided dose in patients undergoing total knee replacement. ${ }^{43}$ Treatment lasted 10-14 days, commencing 12-24 hours after surgery with apixaban and enoxaparin and on the evening of surgery with warfarin. Usual exclusion criteria applied, and a mandatory bilateral venography was scheduled for Day 12 after the last study drug dose. Primary efficacy outcome was a composite of VTE and all-cause mortality during treatment. Primary safety outcome was major bleeding, defined as reduction of hemoglobin $>2 \mathrm{~g} / \mathrm{dL}$ and/or requirement of two units of packed red blood cells, need for discontinuing study medication, intracranial, retroperitoneal, intraspinal, or necessitating reoperation or intervention, intrapericardial or fatal. Minor bleeding were all events not meeting these criteria.

A total of 1217 patients were eligible for safety and 856 patients for efficacy analysis. In all apixaban treatment arms, patients had lower primary efficacy event rates than either comparator (Figure 2). The primary outcome decreased with increasing apixaban dose. Efficacy outcome was 9.0\% for $2.5 \mathrm{mg}$ apixaban twice daily and $11.3 \%$ for $5 \mathrm{mg}$ apixaban once daily, compared with $15.6 \%$ in the enoxaparin and $26.6 \%$ in the warfarin group. Total VTE rates were lower in the twice-daily group than in the once-daily regimen. For the composite outcome of proximal DVT or PE and allcause mortality, each apixaban group had a lower event rate $(0 \%-2.7 \%)$ compared with the enoxaparin group (4.6\%), which was not statistically significant. For both once-daily and twice-daily apixaban regimens, a significant dose-related increase in the incidence of bleeding events was noted. Incidence ranged from $0 \%$ (2.5 $\mathrm{mg}$ twice daily) to $3.3 \%$ (20 mg once daily). No major bleeding was observed in either the enoxaparin group or the warfarin group. Minor bleeding incidences during apixaban, enoxaparin, and warfarin treatment were $0.7 \%-7.2 \%, 4.0 \%$, and $5.3 \%$, respectively. For patients receiving apixaban, rates of myocardial infarction $(0.44 \%)$ and stroke $(0.55 \%)$ were in line with other studies.

The authors concluded that $2.5 \mathrm{mg}$ apixaban twice daily started 12-24 hours after surgery exhibits a favorable benefitrisk profile compared with standards of care. Consequently, apixaban $2.5 \mathrm{mg}$ twice daily was chosen in three large Phase III trials evaluating the efficacy and safety of apixaban thromboprophylaxis against standard of care enoxaparin.

In ADVANCE-1, the North American regimen of enoxaparin $30 \mathrm{mg}$ twice daily was tested against oral $2.5 \mathrm{mg}$ apixaban twice daily in elective knee replacement for 10-14 days, started 12-24 hours post surgery. ${ }^{14}$ Primary efficacy outcome was a composite of asymptomatic and symptomatic DVT, nonfatal PE, and death from any cause during treatment. Definition of major bleeding was acute clinically overt bleeding accompanied by one or more of 
the following: a decrease in hemoglobin concentration of $2 \mathrm{~g} / \mathrm{dL}$ or more during 24 hours, transfusion of two or more units of packed red blood cells, critical site bleeding (intracranial, intraspinal, intraocular, pericardial, or retroperitoneal bleeding), bleeding leading to reoperation, intramuscular bleeding with compartment syndrome, or fatal bleeding.

Patients were followed for 60 days after anticoagulation therapy was stopped. In total, 1157 patients receiving apixaban and 1588 patients receiving enoxaparin were included in the primary efficacy analysis. The rate of primary efficacy outcome was $9.0 \%$ with apixaban as compared with $8.8 \%$ with enoxaparin (relative risk [RR] 1.02 [95\% confidence interval (CI) 0.78-1.32]). Secondary efficacy endpoint of major VTE event was seen in $2.1 \%$ and $1.6 \%$, respectively. Of note, PE fatal and nonfatal occurred in 1.0\% (apixaban) versus $0.4 \%$ (enoxaparin). Apixaban did not meet the prespecified statistical criteria for noninferiority, because event rates in both treatment arms were significantly lower than expected and the study was underpowered to prove noninferiority for efficacy. Major bleeding events occurred in $0.7 \%$ with apixaban and $1.4 \%$ with enoxaparin $(P=0.053)$. The incidence of the composite safety endpoint major bleeding and clinically relevant nonmajor bleeding was $2.9 \%$ with apixaban and $4.3 \%$ with enoxaparin $(P=0.03)$. Other adverse events, such as hepatotoxicity and arterial thromboembolism, were rare in both groups. The authors concluded that apixaban $2.5 \mathrm{mg}$ twice daily and enoxaparin have a similar efficacy that is within limits and which should be acceptable to clinicians. Furthermore, apixaban was found to reduce the risk of bleeding complications.

In ADVANCE-2, patients undergoing elective uni- or bilateral total knee replacement were randomly allocated to receive oral apixaban $2.5 \mathrm{mg}$ twice daily or enoxaparin $40 \mathrm{mg}$ subcutaneously once daily. ${ }^{16}$ Apixaban was started 12-24 hours after wound closure and enoxaparin 12 hours before surgery, and both drugs were continued for 10-14 days when bilateral ascending venography was scheduled. Patients had follow-up assessments 30 days and 60 days after the last dose of study drug. The primary outcome was the composite of asymptomatic and symptomatic DVT, nonfatal PE, and allcause death during treatment. Bleeding events were classified as major, nonmajor, and clinically relevant nonmajor.

A total of 1528 patients were eligible for primary efficacy analysis in the apixaban group, as were 1529 in the enoxaparin group. Primary outcome was reported in $15 \%$ of apixaban patients and $24 \%$ of enoxaparin patients (RR 0.62 , $95 \%$ CI $0.51-0.74, P<0.0001$ ). Major or clinically relevant nonmajor bleeding occurred in $4 \%$ of patients receiving apixaban and $5 \%$ of those treated with enoxaparin. Of nine major bleeding events with apixaban, five occurred before the first dose of apixaban. Elevated liver enzyme levels were equally reported in both study groups. The authors concluded that oral twice-daily $2.5 \mathrm{mg}$ apixaban offers a convenient and more effective alternative to $40 \mathrm{mg}$ enoxaparin daily without increased bleeding.

In ADVANCE-III, apixaban $2.5 \mathrm{mg}$ twice daily was given 12-24 hours post surgery and tested against enoxaparin $40 \mathrm{mg}$ once daily, which was on the evening before surgery in patients undergoing hip replacement surgery. ${ }^{15}$ Both regimens were given for 35 days. Patients were followed for 60 days after the last intended study drug dose. For all patients, bilateral venography was scheduled on Day 35 . Primary efficacy outcome was the composite of asymptomatic or symptomatic DVT, nonfatal PE, or death from any cause during the treatment period. Primary safety outcome was bleeding during treatment, defined as in the aforementioned studies.

Primary efficacy analysis was performed in 1949 apixaban-treated patients and in 1917 enoxaparin-treated patients. The primary efficacy outcome occurred in 1.4\% and $3.9 \%$ of patients, respectively (RR $0.36,95 \%$ CI $0.22-0.54$; $P<0.001$ for both noninferiority and superiority). The composite of outcome of major and clinically relevant nonmajor bleeding occurred in $4.8 \%$ versus $5.0 \%(P=0.72)$. Hepatic enzyme elevations as well as arterial thromboembolic events were rare in both groups. The authors concluded that apixaban at a dose of $2.5 \mathrm{mg}$ twice daily was superior to enoxaparin at a dose of $40 \mathrm{mg}$ per day, preventing one episode of major VTE for each 147 patients treated, without adding to the risk of bleeding.

\section{Clinical impact of VTE prophylaxis with apixaban in major orthopedic surgery General aspects of implementation of new oralVTE prophylaxis into daily practice}

First of all, patients and staff need to be reminded that change of VTE prophylaxis from injectable drugs to oral anticoagulants does not indicate that VTE is no longer a relevant risk and therefore that lower compliance is acceptable. On the contrary, because VTE risk remains high for weeks after hip or knee joint replacement, a daily administration of VTE prophylaxis is indispensable. It is known that patient compliance with long-term prophylaxis decreases after discharge, if injectable anticoagulants are used. ${ }^{7}$ Therefore, the use of oral 
anticoagulants should increase the acceptance of prolonged VTE prophylaxis, if patients are adequately instructed.

Secondly, hospital staff need to be aware that timing of the first dose of VTE prophylaxis is essential for the balance between effective VTE prevention and bleeding risks after major surgery. In contrast to LMWHs, which in many Western countries are started on the evening before surgery (in contrast to a postsurgical start in North America), the first dose of all new oral anticoagulants is given post surgery. However, the timing of the first dose of VTE prophylaxis post surgery depends on the substance used and needs to be carefully implemented. Historically, the parenteral anticoagulant fondaparinux has been shown to increase bleeding complications after MOS, if started before 6 hours post surgery, which leads to adjusted recommendations for fondaparinux. ${ }^{44}$

Based on these experiences, the timing of postsurgical oral thromboprophylaxis has been carefully considered. With apixaban prophylaxis, the first dose is given after 12-24 hours post surgery, allowing for a long time for primary hemostasis at surgical sites (Table 1). This is in contrast to other NOACs: dabigatran is started after 1-4 hours post surgery already, but with an initial dose of only 50\% (110 mg instead of $220 \mathrm{mg}$, whereas rivaroxaban is started with a first full initial dose of $10 \mathrm{mg}$ after 6-10 hours post surgery).

Furthermore, timing of oral thromboprophylaxis and removal of spinal catheters is dependent on the NOAC in use, due to different half-lives, once- or twice-daily regimens, and a contraindication for dabigatran in patients with spinal catheters. Consequently, written standard operating procedures should be implemented before thromboprophylaxis is switched from injectable agents to NOAC.

Finally, the duration of postoperative thromboprophylaxis after MOS is determined by the fact that VTE risk remains high for weeks after hip or knee replacement. Therefore, current guidelines recommend prolonged thromboprophylaxis in these patients with a minimum of 10-14 days (Level 1B), but prolongation until Day 35 should be considered in MOS (Level 2B). ${ }^{45}$ However, these recommendations are similar for all types of medical thromboprophylaxis in use and do not differ with NOAC thromboprophylaxis.

\section{Dose adjustments in special populations}

For patients undergoing MOS, all new oral FXa inhibitors are currently contraindicated in patients with a creatinine clearance below $15 \mathrm{~mL} / \mathrm{min}$. Due to the low proportion of renal elimination of oral FXa inhibitors apixaban, edoxaban, and rivaroxaban, no dose adjustments are necessary if creatinine clearance is above $15 \mathrm{~mL} / \mathrm{min}$. This is in contrast to dabigatran, which is contraindicated at a creatinine clearance below $30 \mathrm{~mL} / \mathrm{min}$. Furthermore, dose adjustments are necessary in patients older than 75 years or with a creatinine clearance between $30 \mathrm{~mL} / \mathrm{min}$ and $50 \mathrm{~mL} / \mathrm{min}(150 \mathrm{mg}$ instead of $220 \mathrm{mg}$ once daily).

\section{Monitoring of NOAC thromboprophylaxis}

Similar to the VTE prophylaxis with LMWH or fondaparinux, no routine monitoring of NOAC prophylaxis is necessary. All new oral anticoagulants display a predictive dose response, which allows for standard dosing independent from laboratory test results. However, compared with LMWH or fondaparinux, an important difference exists. All oral FXa inhibitors produce a dose-dependent increase of prothrombin time (PT), INR, and clotting times. ${ }^{46,47}$ Of note, values need to be interpreted with caution, because standard measurements are not calibrated for these substances and short half-lives of FXa inhibitors would produce fast changes of test results within hours. Furthermore, a number of PT assays are available, which have vastly variable sensitivity to FXa inhibitors, and normal values as well as INR values above 3 may be found despite therapeutic anticoagulation. Consequently, interpretation of PT results would require specific calibration curves, the knowledge of the assay used to measure PT, and the exact timing of drug intake and blood sampling. This is in strict contrast to PT or INR measurements during vitamin $\mathrm{K}$ antagonist therapy (VKA), where values remain fairly constant during the day and an INR range between 2 and 3 indicates adequate VKA treatment, while values outside of this range indicate a sub- or supratherapeutic anticoagulant effect of VKA. Therefore, PT or INR monitoring is not recommended with oral FXa inhibitors. However, new tests are currently being implemented to allow for exact quantification of oral direct FXa inhibitors, based on the measurement of anti-FXa activity via chromogenic FXa assays. ${ }^{48-52}$

In contrast to the oral direct FXa inhibitors, dabigatran as a direct thrombin inhibitor significantly alters partial thromboplastin time (PTT) and, to a lesser extent, PT and INR values. Again, these changes must not be interpreted in a similar way to heparin or VKA therapy, because test results do not necessarily correlate with dabigatran therapy. Specific tests such as HemoClot are available to monitor dabigatran therapy. ${ }^{53}$

Taken together, neither normal nor abnormal test values of PTT, PT, INR, or clotting times give any indication of the quality of NOAC therapy, and interpretation of test results needs to reflect type and dosage of NOAC, interval between 
intake and blood sampling, and renal and hepatic function. However, routine monitoring is not necessary for NOAC therapy, and specific tests will be available for the rare situations when management of emergency situations requires exact quantification of NOAC activity.

\section{Management of bleeding complications}

In Phase II, all NOACs exhibited a broad therapeutic window with only a slight increase in bleeding complications with higher dosages in dose-escalating studies in MOS. ${ }^{43,54-56}$ These results were supported in large Phase III trials, where severe bleeding complications were rare. Consequently, most bleeding complications seen after MOS will not relate to the anticoagulant in use but rather to patient-specific factors or surgical complications. Furthermore, most bleeding complications will present as nonsevere bleeding, which can simply be managed by reducing or interrupting NOAC prophylaxis for a short period of time. Because all NOACs are short acting with half-lives comparable with LMWH prophylaxis, no change of standard of care is necessary in nonsevere bleeding situations. Obviously, standard management of bleeding complications may include local compression, surgical, endoscopic, or interventional therapy as well as hemodynamic stabilization with fluids or whole-blood transfusions.

In cases of severe bleeding, oral FXa inhibitor activity may be antagonized using prothrombin complex concentrates (PCC), recombinant factor VIIa (rVIIa), or factor eight inhibitor bypassing activator (FEIBA or aPCC). Recombinant factor VII or FEIBA/aPCC may also be considered as treatment options in severe bleeding complications of dabigatrantreated patients. ${ }^{57,58}$

In case of suspected or suicidal overdosing of oral FXa inhibitors, gastrointestinal uptake can be reduced by activated carbon application within 3 hours after intake. In contrast, in patients receiving dabigatran, hemodialysis may reduce drug levels. ${ }^{58}$

The following steps provide a therapeutic guideline for patients with severe bleeding events: (1) delay the next administration of NOAC; (2) if the patient is treated with oral FXa inhibitors, consider activated carbon depending on the intake time; (3) if the patient is treated with dabigatran, consider hemodialysis; (4) consider usual treatment for bleeding, including endoscopic, surgical, or interventional bleeding control, blood transfusion, and fresh frozen plasma; and (5) if bleeding cannot be controlled or emergency surgery is indicated, consider administration of procoagulants such as PCC. If bleeding cannot be controlled, FEIBA or rVIIa may be used according to the guidelines. Of note, neither PCC nor rVIIa is approved for management of NOAC-associated bleeding complications.

\section{Conclusion}

Thromboprophylaxis in MOS is still an important issue, and the development of new oral anticoagulants has led to advances in both efficacy and safety in this indication. Apixaban as one of the new oral direct FXa inhibitors has been shown to be highly effective and safe to prevent VTE complications in patients undergoing elective hip or knee replacement. Provided that personnel and patients are instructed that high treatment compliance is required, it can be expected that apixaban will achieve this benefit over parenteral prophylaxis also in unselected patients in daily care.

Implementation of NOACs in thromboprophylaxis in daily care is simple, but specific pharmacological differences exist between apixaban, rivaroxaban, and dabigatran. Consequently, the choice of substance should reflect local specifics such as pre-existing experience with new oral anticoagulants, use of spinal catheters and timing of removal, proportion of older or renally impaired patients, typically used comedications, and preference of a late postoperative start or a once-daily regimen. Therefore, the authors do not recommend the use of different NOACs for thromboprophylaxis on the same orthopedic ward. Furthermore, we strongly recommend the implementation of standard operating procedures for NOAC use in orthopedic surgery to enhance compliance and avoid errors in dosing and management problems (such as initiating prophylaxis too early or too late), or catheter removal without interruption of NOAC, all of which may cause harm to the patient.

If oral FXa inhibitors such as apixaban are used in MOS prophylaxis, no dose adjustments for age, gender, or renal function are necessary, provided that renal function has a glomerular filtration rate above $15 \mathrm{~mL} / \mathrm{min}$. Furthermore, no routine monitoring is required.

Finally, major bleeding complications will be rare with NOAC thromboprophylaxis, and management of these will be comparable with that of bleeding complications in patients receiving LMWH prophylaxis, because all NOACs have predictable pharmacokinetics with comparatively short half-lives.

\section{Disclosures}

$\mathrm{SW}, \mathrm{KH}$, and JBW were investigators in numerous Phase III trials investigating apixaban, rivaroxaban, edoxaban, and dabigatran in VTE prophylaxis, VTE treatment, and stroke 
prevention in atrial fibrillation. SW received honoraria from Bayer Healthcare for lectures. JBW received honoraria from Bayer Healthcare, Bristol-Myers Squibb, Pfizer, and Boehringer Ingelheim for lectures; serves as a member of advisory boards of Bayer Healthcare, Bristol-Myers Squibb, and Pfizer; and received support from Bayer Healthcare for an investigator-initiated registry on VTE prevention in major orthopedic surgery.

\section{References}

1. Hirsh J, Bauer KA, Donati MB, et al. American College of Chest Physicians. Parenteral anticoagulants: American College of Chest Physicians Evidence-based Clinical Practice Guidelines (8th ed). Chest. 2008;133(Suppl 6):141-159.

2. Hirsh J, Guyatt G, Albers GW, et al; American College of Chest Physician. Antithrombotic and thrombolytic therapy: American College of Chest Physicians Evidence-based Clinical Practice Guidelines (8th ed). Chest. 2008;133(Suppl 6):110-112.

3. Bergqvist D, Benoni G, Björgell O, et al. Low-molecular-weight heparin (enoxaparin) as prophylaxis against venous thromboembolism after total hip replacement. $N$ Engl J Med. 1996;335(10):696-700.

4. Adolf J, Fritsche HM, Haas S, et al. Comparison of 3,000 IU aXa of the low molecular weight heparin certoparin with 5,000 IU aXa in prevention of deep vein thrombosis after total hip replacement. German Thrombosis Study Group. Int Angiol. 1999;18(2):122-126.

5. Lassen MR, Borris LC, Anderson BS, et al. Efficacy and safety of prolonged thromboprophylaxis with a low molecular weight heparin (dalteparin) after total hip arthroplasty: the Danish Prolonged Prophylaxis (DaPP) Study. Thromb Res. 1998;89(6):281-287.

6. Blanchard J, Meuwly JY, Leyvraz PF, et al. Prevention of deep-vein thrombosis after total knee replacement. Randomised comparison between a low-molecular-weight heparin (nadroparin) and mechanical prophylaxis with a foot-pump system. J Bone Joint Surg Br. 1999;81(4):654-659.

7. Wilke T, Moock J, Müller S, Pfannkuche M, Kurth A. Nonadherence in outpatient thrombosis prophylaxis with low molecular weight heparins after major orthopaedic surgery. Clin Orthop Relat Res. 2010;468(9):2437-2453.

8. Bergqvist D, Jönsson B. Cost-effectiveness of prolonged administration of a low molecular weight heparin for the prevention of deep venous thrombosis following total hip replacement. Value Health. 1999;2(4):288-294.

9. Turpie AG, Bauer KA, Eriksson BI, Lassen MR. Fondaparinux vs enoxaparin for the prevention of venous thromboembolism in major orthopedic surgery: a meta-analysis of 4 randomized double-blind studies. Arch Intern Med. 2002;162(16):1833-1840.

10. Eriksson BI, Dahl OE, Rosencher N, et al; RE-NOVATE Study Group. Dabigatran etexilate versus enoxaparin for prevention of venous thromboembolism after total hip replacement: a randomised, double-blind, non-inferiority trial. Lancet. 2007;370(9591):949-956.

11. Eriksson BI, Borris LC, Friedman RJ, et al; RECORD1 Study Group. Rivaroxaban versus enoxaparin for thromboprophylaxis after hip arthroplasty. N Engl J Med. 2008;358(26):2765-2775.

12. Lassen MR, Ageno W, Borris LC, et al; RECORD3 Investigators. Rivaroxaban versus enoxaparin for thromboprophylaxis after total knee arthroplasty. N Engl J Med. 2008;358(26):2776-2786.

13. Turpie AG, Lassen MR, Davidson BL, et al; RECORD4 Investigators. Rivaroxaban versus enoxaparin for thromboprophylaxis after total knee arthroplasty (RECORD4): a randomised trial. Lancet. 2009;373(9676):1673-1680.

14. Lassen MR, Raskob GE, Gallus A, Pineo G, Chen D, Portman RJ. Apixaban or enoxaparin for thromboprophylaxis after knee replacement. N Engl J Med. 2009;361(6):594-604.
15. Lassen MR, Gallus A, Raskob GE, Pineo G, Chen D, Ramirez LM; ADVANCE-3 Investigators. Apixaban versus enoxaparin for thromboprophylaxis after hip replacement. $N$ Engl J Med. 2010;363(26): 2487-2498.

16. Lassen MR, Raskob GE, Gallus A, Pineo G, Chen D, Hornick P; ADVANCE-2 investigators. Apixaban versus enoxaparin for thromboprophylaxis after knee replacement (ADVANCE-2): a randomised double-blind trial. Lancet. 2010;375(9717):807-815.

17. Raskob G, Cohen AT, Eriksson BI, et al. Oral direct factor Xa inhibition with edoxaban for thromboprophylaxis after elective total hip replacement. A randomised double-blind dose-response study. Thromb Haemost. 2010;104(3):642-649.

18. Fuji T, Fujita S, Tachibana S, Kawai Y. A dose-ranging study evaluating the oral factor $\mathrm{Xa}$ inhibitor edoxaban for the prevention of venous thromboembolism in patients undergoing total knee arthroplasty. J Thromb Haemost. 2010;8(11):2458-2468.

19. Luettgen JM, Bozarth TA, Bozarth JM, et al. In vitro evaluation of apixaban, a novel, potent, selective and orally bioavailable factor Xa inhibitor [abstract no 4130]. Presented at ASH 2006. Blood (ASHAnnual Meeting Abstracts). November 16, 2006;108(11).

20. Jiang X, Crain EJ, Luettgen JM, Schumacher WA, Wong PC. Apixaban, an oral direct factor Xa inhibitor, inhibits human clot-bound factor Xa activity in vitro. Thromb Haemost. 2009;101(4):780-782.

21. He K, He B, Grace JE, et al. Preclinical pharmacokinetic and metabolism of apixaban, a potent and selective factor Xa inhibitor [abstract no 910]. Presented at ASH. Blood (ASH Annual Meeting Abstracts). November 16, 2006;108(11).

22. Frost C, Yu Z, Nepal S, et al. Apixaban, a direct factor Xa inhibitor: single-dose pharmacokinetics and pharmacodynamics of an intravenous formulation [abstract no 142]. J Clin Pharmacol. 2008;48(9):1132.

23. Frost $\mathrm{C}, \mathrm{Yu} \mathrm{Z}$, Moore $\mathrm{K}$, et al. Apixaban, an oral direct factor $\mathrm{Xa}$ inhibitor: multiple-dose safety, pharacokinetics, and pharmacodynamics in healthy subjects [abstract no PM-664]. Prestented at ISTH 2007. J Thromb Haemost. 2007;5(Suppl 2):P-M-664.

24. Raghavan N, Frost CE, Yu Z, et al. Apixaban metabolism and pharmacokinetics after oral administration to humans. Drug Metab Dispos. 2009;37(1):74-81.

25. Morishima Y, Furugohri T, Isobe K, et al. In vitro characteristics, anticoagulant effects and in vivo antithrombotic efficacy of a novel, potent and orally active direct factor Xa inhibitor, DU-176b [abstract no 1862]. Presented at ASH 2004. Blood (ASHAnnual Meeting Abstracts). November 16, 2004;104(11).

26. Shibano T, Tsuji N, Kito F, et al. Effects of DU-176b, a novel direct factor Xa inhibitor, on prothrombinase activity and platelet aggregation in vitro [abstract no PT-642]. Presented at ISTH 2007. J Thromb Haemost. 2007;5(Suppl 2): P-T-642.

27. Roehrig S, Straub A, Pohlmann J, et al. Discovery of the novel antithrombotic agent 5-chloro-N-(\{(5S)-2-oxo-3-[4-(3-oxomorpholin4-yl)phenyl]-1,3-oxazolidin-5-yl\}methyl)thiophene-2-carboxamide (BAY 59-7939): an oral, direct factor Xa inhibitor. J Med Chem. 2005;48(19):5900-5908.

28. Weinz C, Radtke M, Schmeer K, et al. In vitro metabolism of BAY 59-7939 - an oral, direct factor Xa inhibitor [abstract no 195]. Drug Metab Rev. 2004;36(Suppl 1):98.

29. Gross PL, Weitz JI. New anticoagulants for treatment of venous thromboembolism. Arterioscler Thromb Vasc Biol. 2008;28(3): 380-386.

30. Weinz C, Schwartz T, Pleiss U, et al. Metabolism and distribution of [14C]BAY 59-7939 - an oral, direct factor Xa inhibitor - in rat, dog and human [abstract no 196]. Drug Metab Rev. 2004;36(Suppl 1):98.

31. Laux V, Perzborn E, Kubitza D, Misselwitz F, et al. Preclinical and clinical characteristics of rivaroxaban: a novel, oral, direct factor Xa inhibitor. Semin Thromb Hemost. 2007;33(5):515-523.

32. Rautio J, Humphreys JE, Webster LO, et al. In vitro p-glycoprotein inhibition assays for assessment of clinical drug interaction potential of new drug candidates: a recommendation for probe substrates. Drug Metab Dispos. 2006;34(5):786-792. 
33. Kubitza D, Becka M, Wensing G, Voith B, Zuehlsdorf M. Safety, pharmacodynamics, and pharmacokinetics of BAY 59-7939 - an oral, direct Factor Xa inhibitor - after multiple dosing in healthy male subjects. Eur J Clin Pharmacol. 2005;61(12):873-880.

34. Kubitza D, Becka M, Voith B, Zuehlsdorf M, Wensing G. Safety, pharmacodynamics, and pharmacokinetics of single doses of BAY 59-7939, an oral, direct factor Xa inhibitor. Clin Pharmacol Ther. 2005;78(4):412-421.

35. Bayer-Inc. Xarelto ${ }^{\circledR}$ (rivaroxaban $10 \mathrm{mg}$ tablets): product monograph [online].

36. Kubitza D, Becka M, Roth A, Mueck W. Dose-escalation study of the pharmacokinetics and pharmacodynamics of rivaroxaban in healthy elderly subjects. Curr Med Res Opin. 2008;24(10):2757-2765.

37. Furugohri T, Isobe K, Honda Y, et al. Pharmacological characterization, antithrombotic and bleeding effects of DU-176b, a novel, potent and orally active direct inhibitor of factor Xa: a wider safety margin of antithrombotic and bleeding effects compared to heparin, LMWH and warfarin [abstract no P1110]. Presented at ISTH; 2005.

38. Zafar MU, Vorchheimer DA, Gaztanaga J, et al. Antithrombotic effects of factor Xa inhibition with DU-176b: Phase-I study of an oral, direct factor Xa inhibitor using an ex-vivo flow chamber. Thromb Haemost. 2007;98(4):883-888.

39. Ayyub MA, El-Moursy SA, Khazindar AM, Abbas FA. Successful treatment of chronic hepatitis $\mathrm{C}$ virus infection with peginterferon alpha-2a and ribavirin in patients with sickle cell disease. Saudi Med J. 2009;30(5):712-716.

40. Ruff CT, Giugliano RP, Antman EM, et al. Evaluation of the novel factor Xa inhibitor edoxaban compared with warfarin in patients with atrial fibrillation: design and rationale for the Effective aNticoaGulation with factor xA next GEneration in Atrial Fibrillation-Thrombolysis In Myocardial Infarction study 48 (ENGAGE AF-TIMI 48). Am Heart J. 160(4):635-641

41. Masumoto H, Yoshigae Y, Watanabe K, et al. In vitro metabolism of edoxaban and the enzymes involved in the oxidative metabolism of edoxaban [abstract]. AAPS J. 2010;12(S2):W4308.

42. Stangier J. Clinical pharmacokinetics and pharmacodynamics of the oral direct thrombin inhibitor dabigatran etexilate. Clin Pharmacokinet. 2008;47(5):285-295.

43. Lassen MR, Davidson BL, Gallus A, Pineo G, Ansell J, Deitchman D The efficacy and safety of apixaban, an oral, direct factor Xa inhibitor, as thromboprophylaxis in patients following total knee replacement. J Thromb Haemost. 2007;5(12):2368-2375.

44. Kwong LM, Muntz JE. Thromboprophylaxis dosing: the relationship between timing of first administration, efficacy, and safety. Am J Orthop (Belle Mead NJ). 2002;31(Suppl 11):16-20.

45. Falck-Ytter Y, Francis CW, Johanson NA, et al. Prevention of VTE in orthopedic surgery patients: antithrombotic therapy and prevention of thrombosis, 9th ed: American College of Chest Physicians Evidence-Based Clinical Practice Guidelines. Chest. 2012;141(Suppl 2):e278S-e325S.
46. Barrett YC, Wang Z, Frost C, Shenker A. Clinical laboratory measurement of direct factor $\mathrm{Xa}$ inhibitors: anti-Xa assay is preferable to prothrombin time assay. Thromb Haemost. 2010;104(6): 1263-1271.

47. Ogata K, Mendell-Harary J, Tachibana M, et al. Clinical safety, tolerability, pharmacokinetics, and pharmacodynamics of the novel factor Xa inhibitor edoxaban in healthy volunteers. J Clin Pharmacol. 2010;50(7):743-753.

48. Karst A, Bakowski-Enzian B, Perzborn E. Monitoring of rivaroxaban: suitability of a well-established chromogenic anti-Factor Xa assay. J Thromb Haemost. 2009;7(Suppl 2):372.

49. Samama MM, Le Flem L, Guinet C, et al. Suitability of chromogenic anti-FXa methods to measure rivaroxaban in human plasma. J Thromb Haemost. 2009;7(Suppl 2):693.

50. Samama M, Amiral J, Guinet C, et al. Specific and rapid measurement of rivaroxaban in plasma using a new, dedicated chromogenic assay. Haemostaseologie. 2010;30:A37.

51. Becker RC, Yang H, Barrett Y, et al. Chromogenic laboratory assays to measure the factor Xa-inhibiting properties of apixaban - an oral, direct and selective factor Xa inhibitor. J Thromb Thrombolysis. 2011;32(2): $183-187$.

52. Lindahl TL, Baghaei F, Blixter IF, et al; Expert Group on Coagulation of the External Quality Assurance in Laboratory Medicine in Sweden. Effects of the oral, direct thrombin inhibitor dabigatran on five common coagulation assays. Thromb Haemost. 2011;105(2):371-378.

53. Stangier J, Feuring M. Using the HEMOCLOT direct thrombin inhibitor assay to determine plasma concentrations of dabigatran. Blood Coagul Fibrinolysis. 2012;23(2):138-143.

54. Turpie AG, Fisher WD, Bauer KA, et al; OdiXa-Knee Study Group. BAY 59-7939: an oral, direct factor Xa inhibitor for the prevention of venous thromboembolism in patients after total knee replacement. A phase II dose-ranging study. J Thromb Haemost. 2005;3(11):2479-2486.

55. Eriksson BI, Dahl OE, Büller HR, et al; BISTRO II Study Group. A new oral direct thrombin inhibitor, dabigatran etexilate, compared with enoxaparin for prevention of thromboembolic events following total hip or knee replacement: the BISTRO II randomized trial. JThromb Haemost. 2005;3(1):103-111.

56. Eriksson BI, Borris LC, Dahl OE, et al; ODIXa-HIP Study Investigators A: a once-daily, oral, direct Factor Xa inhibitor, rivaroxaban (BAY 59-7939), for thromboprophylaxis after total hip replacement. Circulation. 2006;114(22):2374-2381.

57. Eerenberg ES, Kamphuisen PW, Sijpkens MK, Meijers JC, Buller HR, Levi M. Reversal of rivaroxaban and dabigatran by prothrombin complex concentrate: a randomized, placebo-controlled, crossover study in healthy subjects. Circulation. 2011;124(14):1573-1579.

58. van Ryn J, Stangier J, Haertter S, et al. Dabigatran etexilate - a novel, reversible, oral direct thrombin inhibitor: interpretation of coagulation assays and reversal of anticoagulant activity. Thromb Haemost. 2010; 103(6):1116-1127.
Therapeutics and Clinical Risk Management

\section{Publish your work in this journal}

Therapeutics and Clinical Risk Management is an international, peerreviewed journal of clinical therapeutics and risk management, focusing on concise rapid reporting of clinical studies in all therapeutic areas, outcomes, safety, and programs for the effective, safe, and sustained use of medicines. This journal is indexed on PubMed Central, CAS,

\section{Dovepress}

EMBase, Scopus and the Elsevier Bibliographic databases. The manuscript management system is completely online and includes a very quick and fair peer-review system, which is all easy to use. Visit http://www.dovepress.com/testimonials.php to read real quotes from published authors. 